\title{
LA IMPORTANCIA DEL CÓDIGO TIPOGRÁFICO EN EL DISEÑO DE LOS PERIÓDICOS: LA PRENSA Y LOS ANDES, DE LA CIUDAD DE RIOBAMBA
}

THE IMPORTANCE OF THE TYPOGRAPHIC CODE IN THE DESIGN OF NEWSPAPERS DISTRIBUTED IN RIOBAMBA CITY.

\section{RESUMEN}

Currently, the print media face the struggle not to disappear in front of the new digital media. At the local level it is not the exception, in the city of Riobamba seven newspapers circulate and their demand is low due to the digital editions and the ease of obtaining them. The newspapers from La Rioja, La Prensa and Los Andes, put into circulation an average of 2000 and 1000 copies, respectively, including supplements with the aim of reaching other segments. For its layout, typography plays a relevant role, since it is responsible for attracting readers. The general objective of the study was to determine the relationship between the use of typographical codes in the newspapers La Prensa and Los Andes and the preference of the readers of the city of Riobamba. For the development of the research, the quantitative and qualitative approach of correlational design was used, the observation and the survey were used as techniques, the sample was obtained from the economically active population of Riobamba, as results show that there are flaws in the composition and selection of typographies for layout and typography affects the choice of readers.

Palabras clave: Tipografía, Diario Los Andes, Diario La Prensa, periódicos de Riobamba, diseño editorial

\section{ABSTRACT}

Currently, the print media face the struggle not to disappear in front of the new digital media. At the local level it is not the exception, in the city of Riobamba seven newspapers circulate and their demand is low due to the digital editions and the ease of obtaining them. The newspapers from La Rioja, La Prensa and Los Andes, put into circulation an average of 2000 and 1000 copies, respectively, including supplements with the aim of reaching other segments. For its layout, typography plays a relevant role, since it is responsible for attracting readers. The general objective of the study was to determine the relationship between the use of typographical codes in the newspapers La Prensa and Los Andes and the preference of the readers of the city of Riobamba. For the development of the research, the quantitative and qualitative approach of correlational design was used, the observation and the survey were used as techniques, the sample was obtained from the economically active population of Riobamba, as results show that there are flaws in the composition and selection of typographies for layout and typography affects the choice of readers.

Keywords: Typography, Los Andes Diary, La Prensa Diary, local newspapers, editorial design

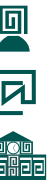

Manuel David Isin Vilema

Universidad Nacional de Chimborazo

misin@unach.edu.ec

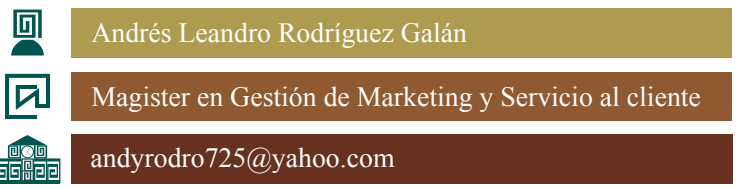

\section{Gabriela Fernanda Vimos Ramírez}

Universidad Nacional de Chimborazo 


\section{INTRODUCCIÓN}

La tipografía, con sus características morfológicas, sus variables de tono, contraste, forma o tamaño, pueden expresar ideas, sentimientos o reforzar el significado de las palabras; ese debe ser el objetivo de escoger una tipografía. "Los lectores rechazan una presentación tipográfica de su periódico que no ofrezca una organización, armonía y facilidad de lectura" (García 1989), una fuente tipográfica transmite los valores que identifican y lo diferencian de la competencia. El uso adecuado de la tipografía, puede hacer la diferencia entre atraer o alejar a los lectores (Vimos 2014) La palabra escrita es el medio de transmisión por excelencia de ideas; por lo tanto, la tipografía dentro de un diseño tiene una gran importancia, porque, tan solo al cambiar el tipo de fuente se genera otro contexto o significado diferente al original. La tipografía es el acompañante y complemento de una imagen dentro de un diseño, cada letra, número o signo de una palabra es por sí misma un elemento gráfico que aporta belleza y significado al total.

Indagar en el extenso mundo de los periódicos y los medios impresos, es adentrarse en el universo de la comunicación a través del papel. En el ámbito nacional, según los datos publicados por la Superintendencia de Telecomunicaciones, y expresados en las cifras expuestas por el Instituto Nacional de Estadísticas y Censos (2014), existen más teléfonos móviles que habitantes y cerca de 1,2 millones posee un teléfono de última generación, esto ha generado que las plataformas digitales declaren la guerra a los medios físicos; con una gran ventaja de los primeros. La cultura visual de Mitchell plantea que la gente cada vez lee menos (Universia 2016).

Ante la presencia de audiencias cada vez más pequeñas, los medios de comunicación impresa de Riobamba, han apuntado a desa- rrollar nuevos subproductos ligados al periódico principal: suplementos infantiles, revistas juveniles, suplementos especializados en deportes o de corte histórico en fechas específicas. Algunos medios de comunicación impresos nacionales e internacionales poseen un manual de estilo y uso tipográfico que les permite diseñar de manera ordenada sus ediciones, principalmente las familias tipográficas utilizadas parten del Manual de Marca, por tanto, es importante el análisis tipográfico de la marca y contenidos, de los productos que ofertan los medios impresos, para determinar los aspectos positivos que deben fortalecer, así también detectar los aspectos negativos que pueden ser sujetos a mejoras.

A pesar de todo, los medios impresos locales trabajan en nuevas estrategias y en nuevas propuestas de productos, con el fin de atraer mayor audiencia. En este papel los códigos tipográficos cumplen un rol muy importante. En Riobamba se producen dos medios impresos locales: La Prensa y Los Andes; quienes a su vez compiten con los periódicos nacionales: Diario Extra, El Comercio, Expreso, El Telégrafo, El Universo.

La investigación se centra en cómo incide el uso adecuado de los códigos tipográficos en la marca y productos de los periódicos: $\mathrm{La}$ Prensa y Los Andes y en la preferencia de los lectores de la ciudad de Riobamba.

"El siglo XX, desde el punto de vista filosófico, se caracterizó por el giro lingüístico $\mathrm{y}$, desde el punto de vista de la cultura popular, por el desarrollo de las tecnologías de la imagen". (Castañares 2007). La cita, incide directamente en la cultura visual de medios impresos, especialmente en los periódicos. Si es verdad que la imagen, por sí sola, debe transmitir una idea, ésta es transitoria y desaparece al separar la vista de ella; por el contrario, la palabra escrita es el medio por excelencia utilizado para la transmisión de mensajes. La correcta combinación entre estos dos elementos 
permitirá conseguir el objetivo que se quiera conseguir con el mensaje. La tipografía, no es sólo un medio de transmisión para un mensaje, sino que, además, es parte importante y fundamental en la configuración visual, de la composición y del atractivo del diseño, ya que cada una tiene su propio carácter y personalidad.

Las nuevas formas de comunicación electrónica no han logrado desplazar a los medios impresos, como se temió en algún momento; más bien, las plataformas virtuales complementan y contribuyen a la difusión de información y al pluralismo de opinión, factores decisivos para el acceso a los derechos ciudadanos y el sostenimiento o la promoción de las formas de vida democráticas.

Lo que han logrado las nuevas tecnologías de la información y la comunicación, es cambiar el sentido de la información, por tal razón ahora "el periódico es un instrumento de información, de educación, de propaganda política y de entretenimiento", así lo expone Guillermo Michel (1990).

En la actualidad, en la era del conocimiento y el auge de plataformas digitales, existe una innumerable presencia de tipos o familias tipográficas, gracias a su fácil difusión y ahora también a su facilidad de creación; los medios de comunicación impresa hacen uso de las mismas e incluso han llegado a desarrollar sus propias fuentes tipográficas.

En el ámbito nacional y local, los medios de comunicación impresa circulan a diario y desde muy tempranas horas de la mañana. Son comercializados por departamentos de venta $\mathrm{y}$ apoyados por voceadores y vendedores, tal y como determinan los departamentos de circulación de estos medios. La demanda diaria de periódicos refleja el interés por la lectura de sus compradores, por obtener una información más desarrollada y descriptiva de la que pueden obtener y visualizar en las plata- formas digitales o en los medios tradicionales (televisión, radio), además de nutrirse con el análisis y la opinión que se ven reflejados en las infografías y páginas editoriales de los periódicos (Vimos 2014).

A partir de reconocer la relevancia de los códigos tipográficos dentro de la composición visual, la presente investigación analiza el uso tipográfico aplicado en el diseño de los periódicos distribuidos en Riobamba: La Prensa y Los Andes y constituye, en cierta forma, una señal a los medios tradicionales, respecto al manejo correcto de los elementos del diseño, principalmente de la tipografía y el análisis de la incidencia que estos pueden tener en la atracción hacia los lectores, la comprensión de los mensajes, la difusión del contenido y por ende el incremento de la demanda.

Para el estudio se cuenta con la investigación realizada por la autora Torres (2013), denominada: "Evolución de la marca La Prensa y su impacto comunicacional en la ciudadanía de Riobamba", esta aportará para desarrollar el análisis tipográfico de las marcas de los diarios y la jerarquía tipográfica utilizada en la diagramación de los medios locales, para determinar los aspectos positivos y negativos que pueden ser sujetos de mejoras o cambios y como objetivo general se ha establecido: determinar la relación entre el uso correcto de los códigos tipográficos en la marca y productos de los periódicos: La Prensa y Los Andes y la preferencia de los lectores de la ciudad de Riobamba. Para dar cumplimiento a este cometido, se ha establecido los siguientes objetivos específicos:

- Realizar un análisis tipográfico de los elementos de la marca y productos de los diarios: La Prensa y Los Andes.

- Determinar los puntos fuertes y críticos sobre el uso de las tipografías en los periódicos locales.

- Identificar la correlación entre la jerarquía tipografía y preferencia por los diarios de la localidad. 


\section{METODOLOGÍA}

El presente corresponde a un artículo de investigación, se empleó los enfoques: cualitativo a través del trabajo de campo aplicando fichas de observación para el análisis semiótico de las tipografías utilizadas por los diarios y cuantitativo a través de encuestas a un número determinado en la muestra para reunir datos numéricos de legibilidad, motivación a la lectura y preferencia.

Es un tipo de investigación Exploratoria, ya que es un tema poco estudiado y del cual se tienen muchas dudas (Hernández, Fernández y Baptista 2010:79). Los resultados de la investigación se convertirán en un panorama aproximado de la influencia de la tipografía en la preferencia los medios impresos locales. Es también una investigación Descriptiva puesto que se describe en base al análisis (Hernández, Fernández y Baptista 2010:80) de los dos diarios locales: La Prensa y Los Andes, cada uno de sus elementos y secciones.

El diseño de la Investigación es correlacional, se busca verificar la existencia de relación entre las variables (Malhotra 2008:604): el uso de los códigos tipográficos y su incidencia en la preferencia en las audiencias lectoras. Se elaboró un estudio de campo, mediante fichas de observación sobre los datos y elementos recolectados en los diarios; a más de ellos es aplicó encuestas a los lectores hombres y mujeres entre 17 y 75 años con nivel de educación secundario y superior que viven en zonas céntricas, urbanizaciones y barrios en toda la ciudad de Riobamba y los cantones de Chimborazo.
Para la selección de la muestra se partió del universo de 263.412 habitantes de la ciudad de Riobamba; dato arrojado por el Instituto Nacional de Estadísticas y Censos (2018), posteriormente se aplicó la siguiente fórmula, empleada para proporciones poblacionales, con los siguientes resultados:

Fórmula para calcular la muestra:

$$
\begin{gathered}
\mathrm{n}=\mathrm{z} 2(\mathrm{p} * \mathrm{q}) \\
\mathrm{e} 2+\quad(\mathrm{z} 2(\mathrm{p} * \mathrm{q})) \\
\mathrm{N}
\end{gathered}
$$

$\mathrm{n}=$ Tamaño de la muestra

$\mathrm{N}=$ Población

$\mathrm{e}=10 \%$

$\mathrm{z}=2.58$

$\mathrm{N}=263412$

$\mathrm{n}=166$ Encuestados

Los principales instrumentos de investigación que se utilizaron para la recolección de información fueron los siguientes:

- Fichas de análisis semiótico de marca y contenidos de los diarios.

- Cuestionario estructurado.

La investigación se desarrolló en la ciudad de Riobamba, a los diarios La Prensa y Los Andes se le solicitó varios ejemplares de su periódico y sus suplementos y posterior se elaboró las fichas de observación para realizar el análisis semiótico tipográfico, luego se determinó la población y en base a la ecuación estadística para proporciones poblacionales se estableció la muestra, se diseñó un cuestionario estructurado el cual se aplicó al segmento seleccionado, a continuación se tabuló, analizó e interpretó los datos obtenidos para elaborar las conclusiones. 


\section{RESULTADOS Y DISCUSIÓN}

Observación de familias tipográficas en Diario la Prensa:

A través de fichas de observación se ha analizado los diferentes tipos de fuentes presentes en el Diario La Prensa y de sus suplementos, como se muestra en las tablas $1-5$, teniendo en cuenta criterios como familia tipográfica, tamaño de fuente, legibilidad y contraste.

Tabla 1: Análisis tipográfico marca La Prensa.

\begin{tabular}{|l|l|l|}
\hline \multicolumn{3}{|c|}{ ANÁLISIS TIPOGRÁFICO } \\
\hline $\begin{array}{l}\text { Investigador: } \\
\text { Los Autores }\end{array}$ & $\begin{array}{l}\text { Medio analizado: } \\
\text { Diario La Prensa }\end{array}$ & $\begin{array}{l}\text { Fecha de análisis: } \\
11 / 04 / 2018\end{array}$ \\
\hline Pieza gráfica de análisis: & Muestra: Portada del día 11/04/2018 \\
\hline & \\
\hline &
\end{tabular}

Fuente: Elaboración propia. 
Tabla 2: Análisis tipográfico titulares Diario La Prensa.

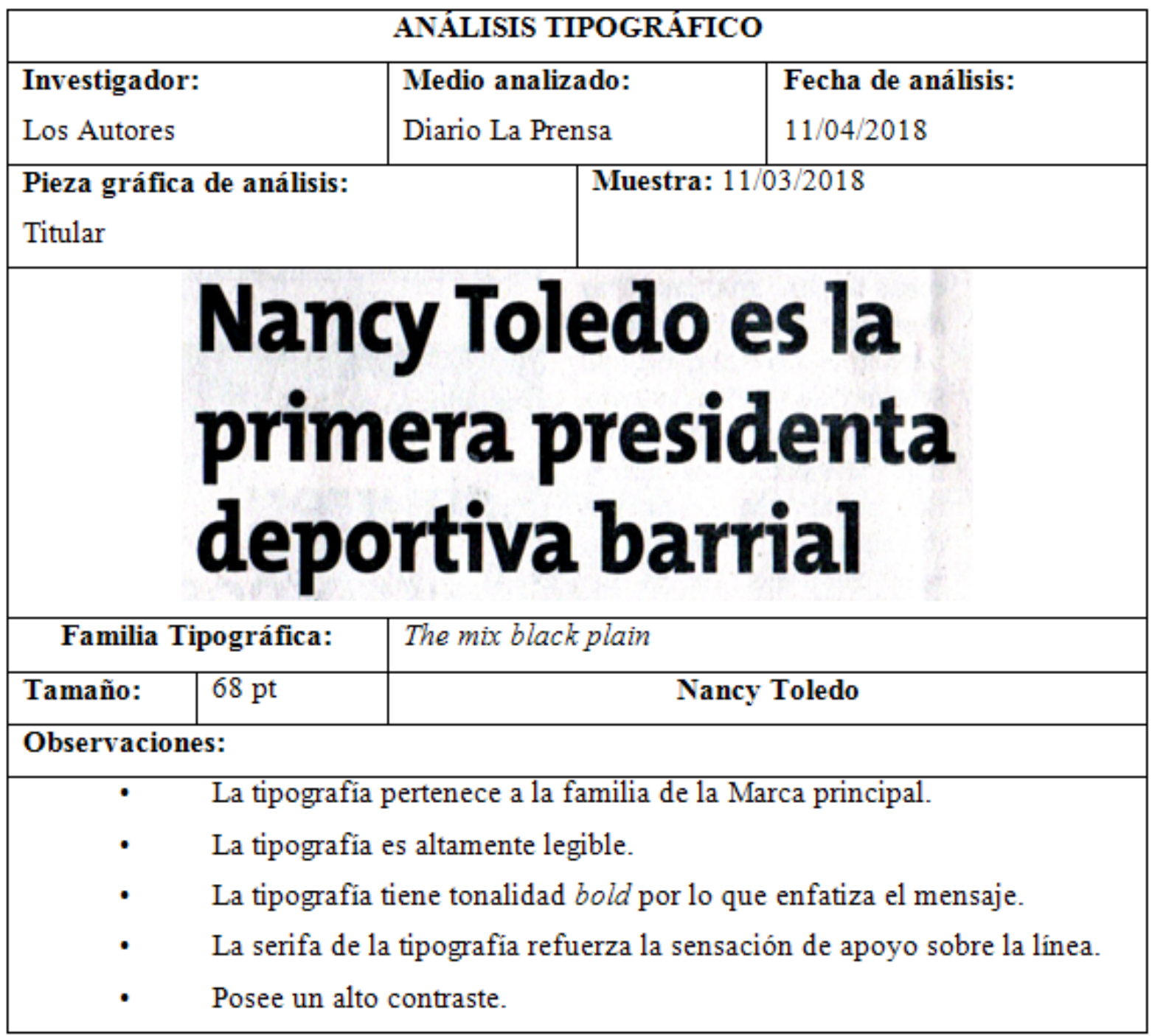

Fuente: Elaboración propia. 
Tabla 3: Análisis tipográfico cuerpo de texto Diario La Prensa.

\begin{tabular}{|c|c|c|c|c|}
\hline \multicolumn{5}{|c|}{ ANÁLISIS TIPOGRÁFICO } \\
\hline \multicolumn{2}{|c|}{$\begin{array}{l}\text { Investigador: } \\
\text { Los Autores }\end{array}$} & $\begin{array}{l}\text { Medio analiz } \\
\text { Diario La Pre }\end{array}$ & ado: & $\begin{array}{l}\text { Fecha de análisis: } \\
11 / 04 / 2018\end{array}$ \\
\hline \multicolumn{3}{|c|}{$\begin{array}{l}\text { Pieza gráfica de análisis: } \\
\text { Cuerpo de texto }\end{array}$} & \multicolumn{2}{|c|}{ Muestra: 11/03/2018 } \\
\hline & \multicolumn{2}{|c|}{$\begin{array}{l}\text { Rıовамва/ La Liga Deportiva } \\
\text { Barrial } 21 \text { de Abril inicia su } \\
\text { actividad y, con ello, aparece } \\
\text { la primera presidenta depor- } \\
\text { tiva a nivel barrial en la } \\
\text { ciudad de Riobamba. }\end{array}$} & \multicolumn{2}{|c|}{$\begin{array}{l}\text { todo para arrancar los tor- } \\
\text { neos que nos corresponde or- } \\
\text { ganizar. Agradezco a todos } \\
\text { los representantes de los } \\
\text { clubes por depositar su con- } \\
\text { fianza en mí al ser electa }\end{array}$} \\
\hline \multicolumn{2}{|c|}{ Familia Tipográfica: } & \multicolumn{3}{|c|}{ Times New Roman } \\
\hline Tamaño: & $12 \mathrm{pt}$ & \multicolumn{3}{|c|}{ La liga Deportiva } \\
\hline \multicolumn{5}{|c|}{ Observaciones: } \\
\hline $\begin{array}{l}\cdot \\
\cdot \\
\cdot \\
\cdot \\
\cdot\end{array}$ & $\begin{array}{l}\text { Es una tip } \\
\text { Permite un } \\
\text { La tipogra: } \\
\text { Es adecua } \\
\text { Posee un a }\end{array}$ & $\begin{array}{l}\text { fia ligth. } \\
\text { ta legibilidad. } \\
\text { lo está modific } \\
\text { ara la lectura. } \\
\text { contraste. }\end{array}$ & ada. & \\
\hline
\end{tabular}

Fuente: Elaboración propia. 
Tabla 4: Análisis tipográfico marca producto "Vida".

\begin{tabular}{|l|l|l|}
\hline \multicolumn{3}{|c|}{ ANALISIS TIPOGRAFICO } \\
$\begin{array}{l}\text { Losvestigador: } \\
\text { Loutores }\end{array}$ & $\begin{array}{l}\text { Medio analizado: } \\
\text { Diario La Prensa }\end{array}$ & $\begin{array}{l}\text { Fecha de análisis: } \\
11 / 04 / 2018\end{array}$ \\
\hline $\begin{array}{l}\text { Pieza gráfica de análisis: } \\
\text { Marca Producto "VIDA" }\end{array}$ & \multicolumn{1}{|c|}{ Muestra: Portada del dia 11/04/2018 } \\
\hline \\
\hline
\end{tabular}

Fuente: Elaboración propia. 
Tabla 5: Análisis tipográfico marca Producto "Hablemos".

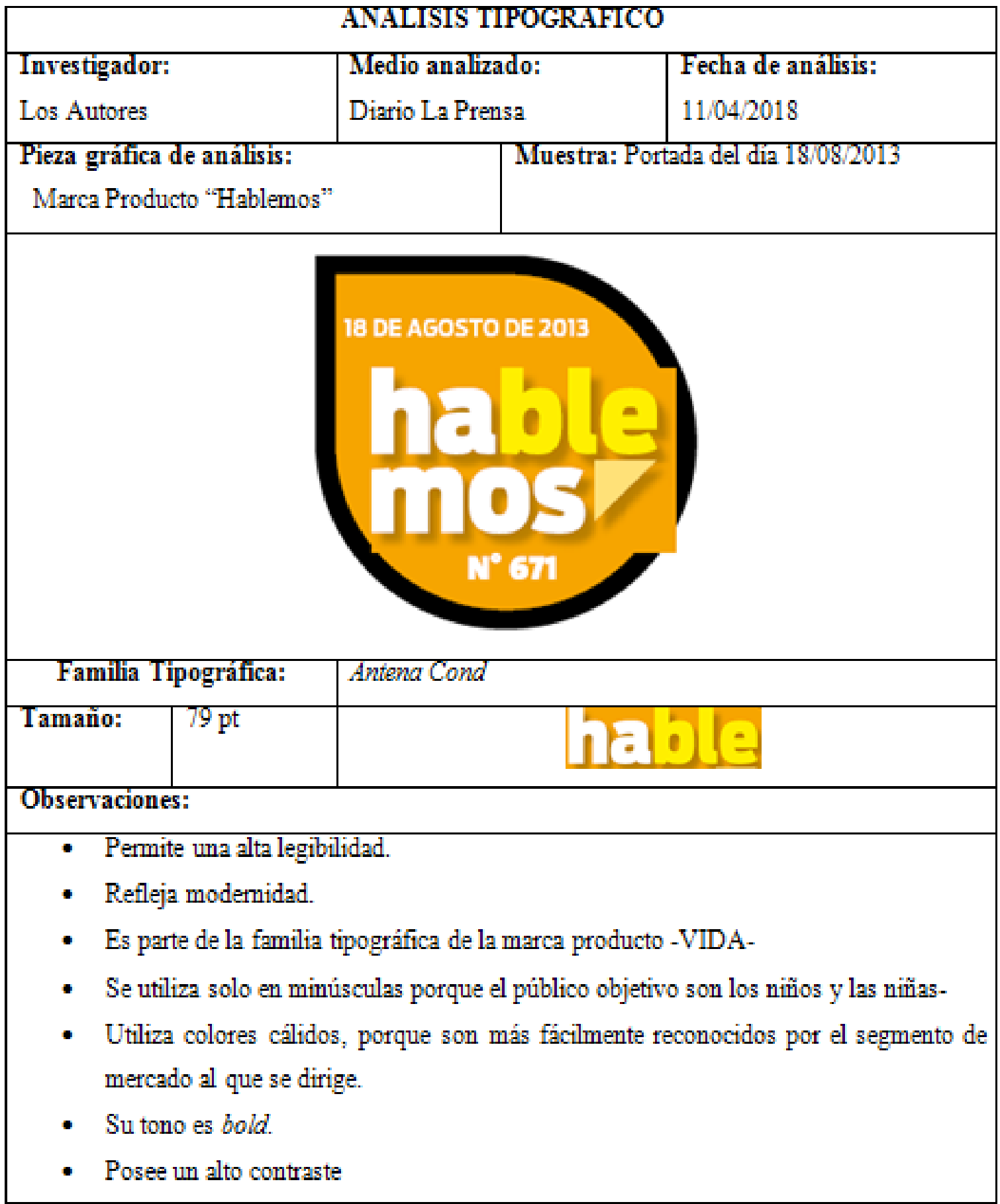

Fuente: Elaboración propia.

Observación de familias tipográficas en Diario los Andes:

A través de fichas de observación se han analizado los diferentes tipos de fuentes presentes en el Diario La Prensa y de sus suplementos, como se muestra en las tablas 6 - 10, teniendo en cuenta criterios como familia tipográfica, tamaño de fuente, legibilidad y contraste. 
Tabla 6: Análisis tipográfico marca Los Andes.

\begin{tabular}{|l|l|l|}
\hline \multicolumn{3}{|c|}{ ANÁLISIS TIPOGRÁFICO } \\
Los Autores & $\begin{array}{l}\text { Medio analizado: } \\
\text { Diario Los Andes }\end{array}$ & $\begin{array}{l}\text { Fecha de análisis: } \\
29 / 04 / 2018\end{array}$ \\
\hline $\begin{array}{l}\text { Pieza gráfica de análisis: } \\
\text { Marca }\end{array}$ & \multicolumn{2}{|c|}{ Muestra: Portada del día 29/04/2018 } \\
\hline \\
\hline
\end{tabular}

Fuente: Elaboración propia 
Tabla 7: Análisis tipográfico titulares Diario Los Andes.

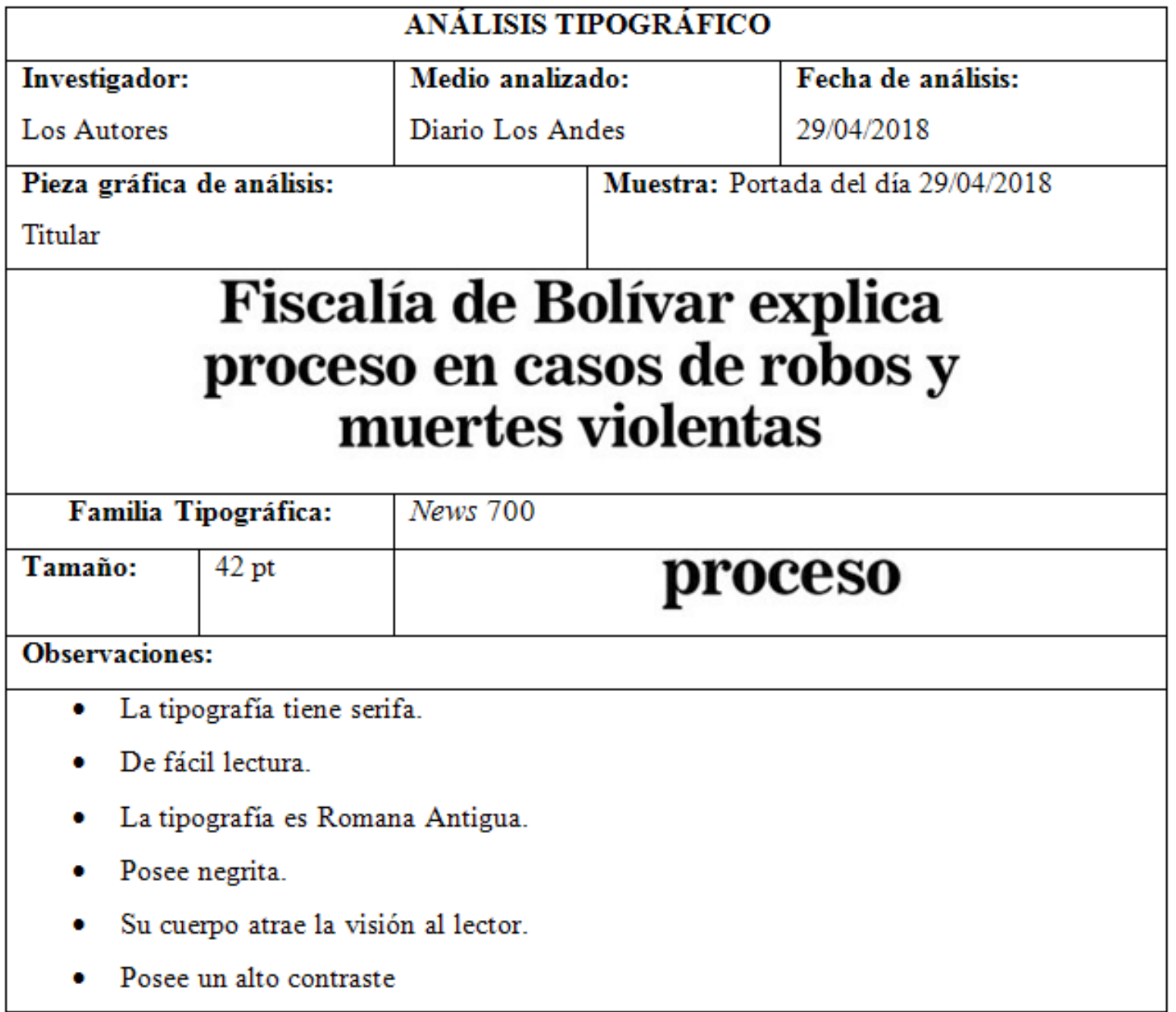

Fuente: Elaboración propia. 
Tabla 8: Análisis tipográfico cuerpo de texto Diario Los Andes.

\begin{tabular}{|c|c|c|c|c|}
\hline \multicolumn{5}{|c|}{ ANALISIS TIPOGRAFICO } \\
\hline \multirow{2}{*}{\multicolumn{2}{|c|}{$\begin{array}{l}\text { Investigador: } \\
\text { Los Autores }\end{array}$}} & \multicolumn{2}{|c|}{ Medio analizado: } & Fecha de análisis: \\
\hline & & \multicolumn{2}{|c|}{ Diario Los Andes } & $29 / 04 / 2018$ \\
\hline \multicolumn{3}{|c|}{$\begin{array}{l}\text { Pieza gráfica de análisis: } \\
\text { Cuerpo de texto }\end{array}$} & \multicolumn{2}{|c|}{ Muestra: Portada del dia 29/04/2018 } \\
\hline \multicolumn{3}{|c|}{$\begin{array}{l}\text { a feria contó con } \\
\text { la presencia de } \\
\text { Daniel Chávez, Di- } \\
\text { rector del MIES Cotopaxi, } \\
\text { Fernanda Pacheco, Reina } \\
\text { del cantón Pujili y de la Pro- } \\
\text { vincia de Cotopaxi, entre } \\
\text { otras autoridades, quienes } \\
\text { disfrutaron de las exposi- } \\
\text { ciones que ofrecieron los di- } \\
\text { ferentes estands, asi como } \\
\text { la participación de los estu- } \\
\text { diantes de varias Unidades } \\
\text { Educativas y ciudadania } \\
\text { que fue para quienes se di- } \\
\text { rige este tipo de eventos. } \\
\text { Además, el Alcalde Fer- }\end{array}$} & $\begin{array}{l}\text { nand } \\
\text { este } \\
\text { jear } \\
\text { provi } \\
\text { co, qu } \\
\text { tón P } \\
\text { "Au } \\
\text { sober } \\
\text { apoyc } \\
\text { jetivo } \\
\text { el an } \\
\text { mejor } \\
\text { bajar } \\
\text { el Mu } \\
\text { ton", }\end{array}$ & $\begin{array}{l}\text { aprovechó } \\
\text { homena- } \\
\text { cina de la } \\
\text { ta Pache- } \\
\text { la del can- } \\
\text { a nueva } \\
\text { mi total } \\
\text { los los ob- } \\
\text { S durante } \\
\text { lan de la } \\
\text { inue tra- } \\
\text { junto con } \\
\text { estro can- }\end{array}$ \\
\hline \multicolumn{2}{|c|}{ Familia Tipográfica: } & \multicolumn{2}{|l|}{ News 700} & \\
\hline Tamaño: & $9,3 \mathrm{pt}$ & & & \\
\hline \multicolumn{5}{|c|}{ Observaciones: } \\
\hline \multicolumn{5}{|c|}{$\begin{array}{l}\text { - La tipografia tiene serifa. } \\
\text { - De fácil lectura. } \\
\text { - La tipografia es Romana Antigua. } \\
\text { - Posee negrita. } \\
\text { - Su cuerpo atrae la visión al lector. } \\
\text { - Posee un alto contraste }\end{array}$} \\
\hline
\end{tabular}

Fuente: Elaboración propia. 
Tabla 9: Análisis tipográfico marca Chiquigrandes.

\begin{tabular}{|c|c|c|c|}
\hline \multicolumn{4}{|c|}{ ANÁLISIS TIPOGRÁFICO } \\
\hline $\begin{array}{l}\text { Investigador: } \\
\text { Los Autores }\end{array}$ & $\begin{array}{l}\text { Medio analizado: } \\
\text { Diario Los Andes }\end{array}$ & $\begin{array}{l}\text { Fecha } \\
29 / 04 / 2\end{array}$ & análisis: \\
\hline $\begin{array}{l}\text { Pieza gráfica de análisis: } \\
\text { "Chiquigrandes" }\end{array}$ & $\mathrm{Mu}$ & ada del c & $29 / 04 / 2015$ \\
\hline $\begin{array}{l}\text { Crubus con } \\
\text { Diario Los Andes }\end{array}$ & $\mathrm{Pe}$ & rlar & $\begin{array}{l}\text { FRASE DE LA SEMANA } \\
\begin{array}{r}\text { Para viajar kejos no } \\
\text { hay mejor nave que } \\
\text { un Ibra:" } \\
\text { Emily Dickson }\end{array}\end{array}$ \\
\hline
\end{tabular}

\begin{tabular}{|c|c|c|}
\hline \multicolumn{2}{|c|}{ Familia Tipográfica: } & Marker Dievla, Big Bimbo NC \\
\hline Tamaño: & $70 \mathrm{pt}$ & 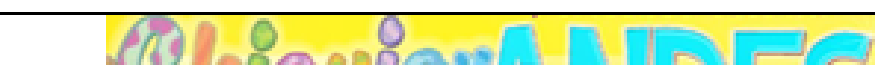 \\
\hline
\end{tabular}

Observaciones:

- Las texturas empleadas dan la sensación de dinamismo.

- Es legible solo en si el tamaño es grande.

- No poseen serifa.

- La combinación de ambas tipografias no es muy estética.

- Existe saturación cromática; el contraste no es el adecuado.

Fuente: Elaboración propia. 
Tabla 10: Análisis tipográfico cuerpo de texto Chiquigrandes.

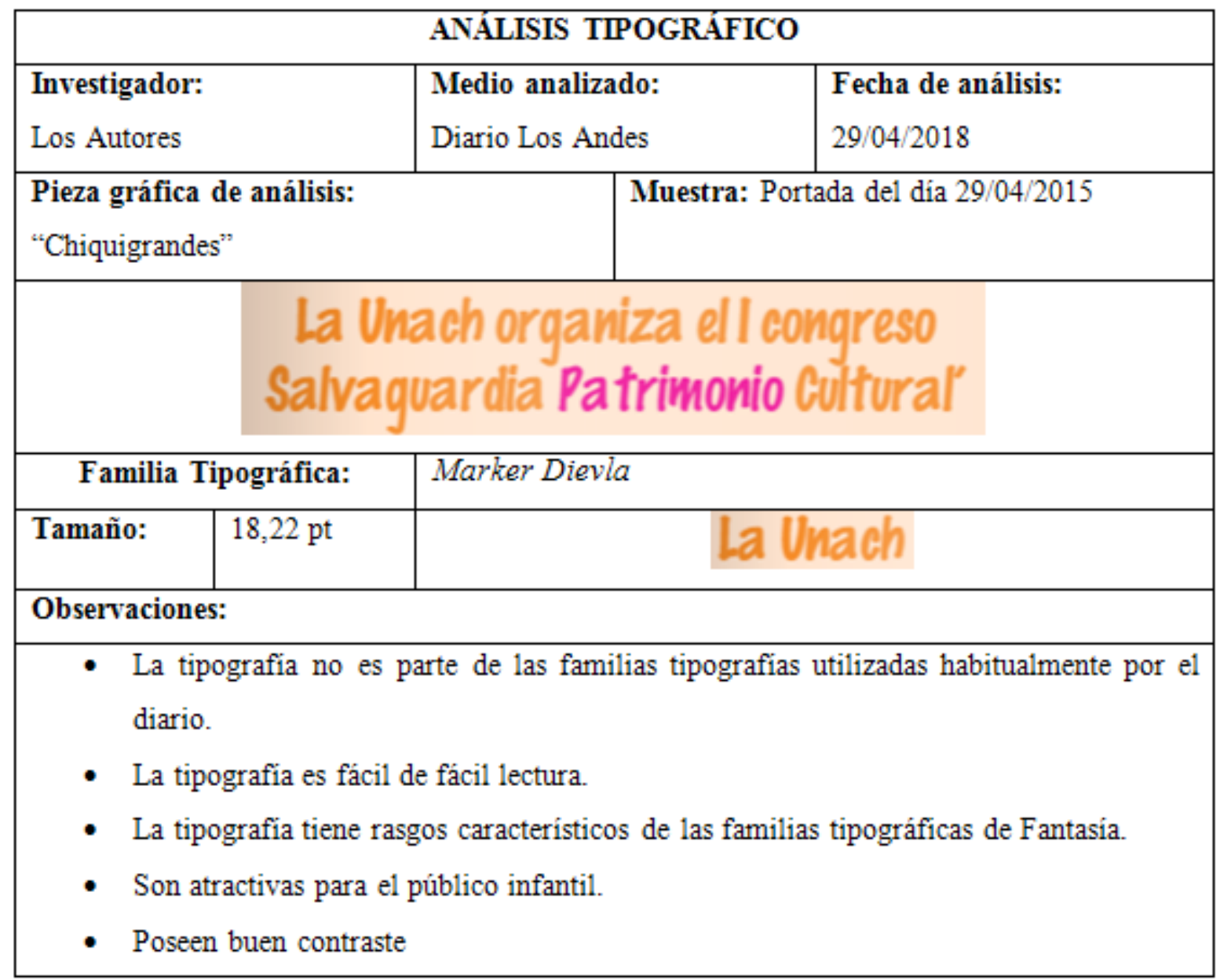

Fuente: Elaboración propia.

Resultados de las encuestas para el análisis tipográfico de Diario la Prensa

Figura 1: Tipografía de la marca Diario La Prensa

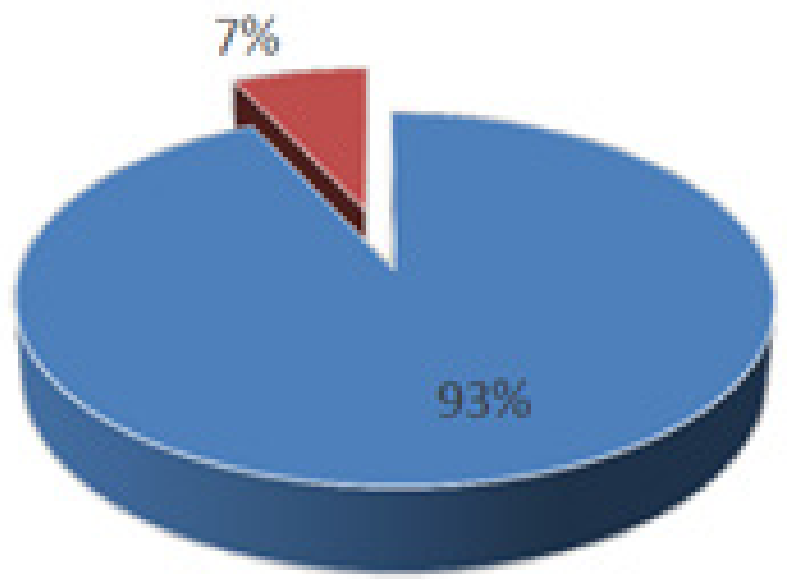

Fuente: Elaboración propia. 
En la figura 1 se muestra que el 93\% de encuestados manifiestan que la letra utilizada en la marca de Diario La Prensa es adecuada; el 7\% de los encuestados manifiestan que no lo es. La marca de La Prensa utiliza una tipografía legible lo que permite a los lectores identificar al diario con solo mirar el logotipo.

Diario La Prensa actualmente está mejor posicionado porque aumentó su productividad y su marca es atractiva a los lectores, esta apreciación justifica el proceso de re-branding que cumplió el diario en el año 2010. La percepción se inclina principalmente a los aspectos positivos; los cambios estructurales establecidos en el proceso de rediseño de la marca, se hacen visibles y agradables a los usuarios.

Figura 2: Legibilidad de los cuerpos de texto Diario La Prensa

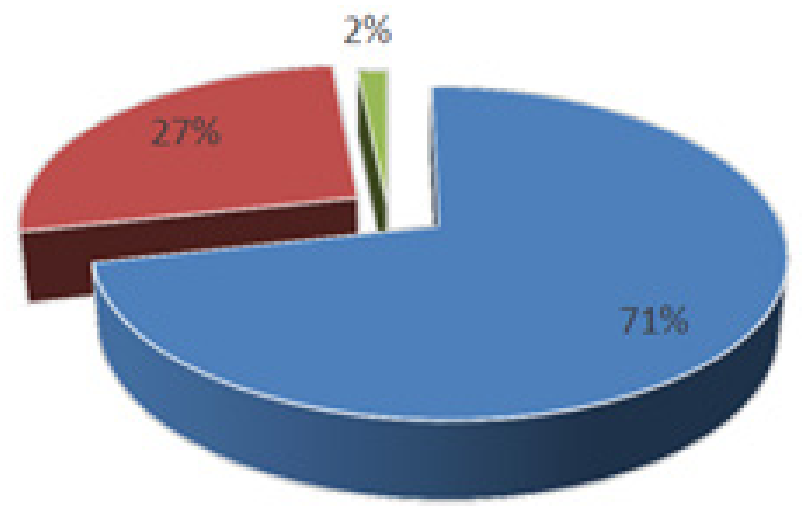

- Mucho

- Medianamente

- Poco

Fuente: Elaboración propia.

Como se observa en la figura 2 , el $71 \%$ de los encuestados consideran que la tipografía utilizada en los cuerpos de textos de Diario la Prensa es muy legible, el 27\% considera que es medianamente legible y el $2 \%$ considera poco legible, en conclusión el cuerpo del texto está acorde a los requerimientos del esquema tradicional del proceso de comunicación (De Buen 2005:35), es decir el lector recibe el mensaje según su relevancia y lo evalua según su convenecia.

Figura 3. Motivación de la tipografía del Diario La Prensa.

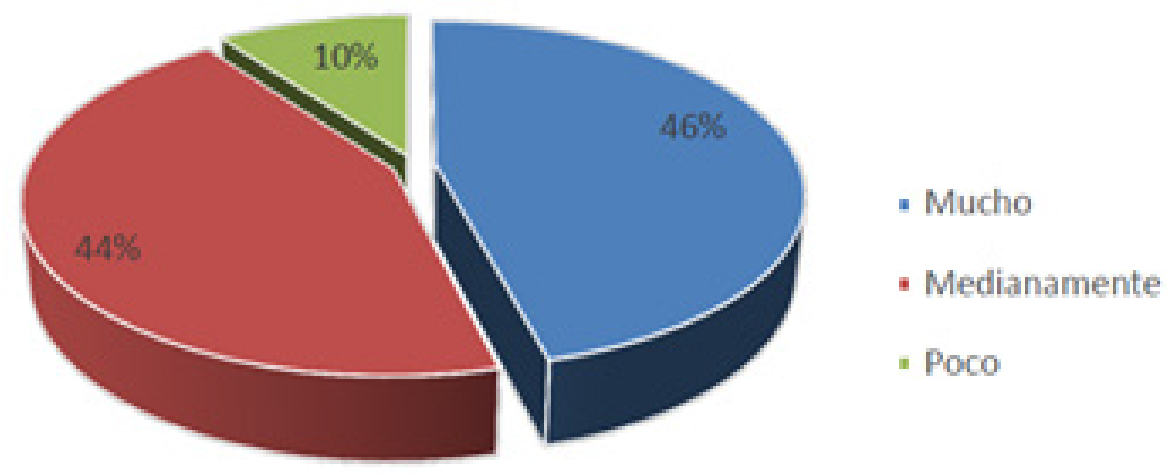

Fuente: Elaboración propia.

$\underset{\text { 回 }}{\text { 回回 }} \underset{\text { 回回 }}{\text { 回 }}$


Según la figura 3, el 46\% de los encuestados considera que las tipografías de los titulares de Diario La Prensa cumplen con la función de motivar a la lectura, el 44\% considera que cumplen medianamente y el $10 \%$ expresa que motiva muy poco. Como criterios extra, los encuestados manifestaron que la tipografía es muy cambiante de un día al otro, añadieron los tamaños son exagerados y los colores poco llamativos. El lector lo primero que descifra es la forma de la estructura, si esta es compleja le tomará meses hacerlo y obligará a dar saltos entre secciones de manera inconsciente e inmediata (De Buen 2005:38)

Figura 4. Influencia de la tipografía en el interés del lector

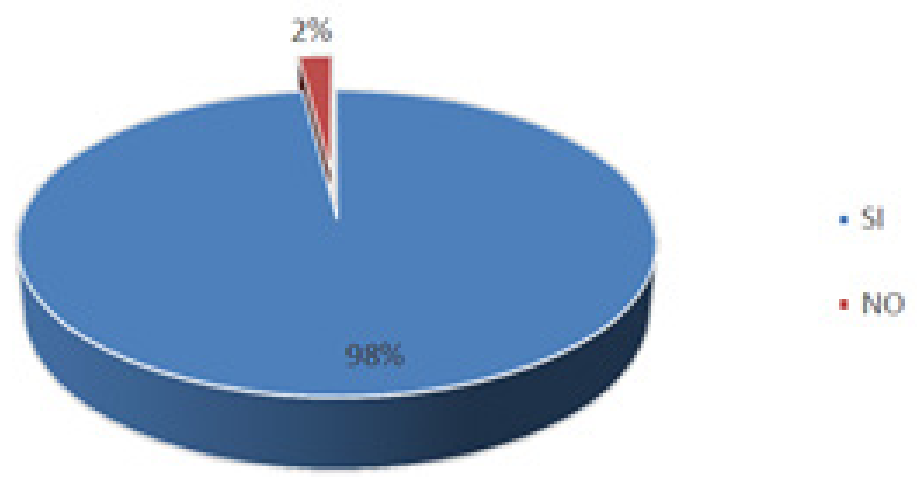

Fuente: Elaboración propia.

En la figura 4 se observa que el $98 \%$ de los encuestados considera que las tipografías bien utilizadas influyen en el interés del lector, solo el $2 \%$ considera que no influye en el interés del lector. Los encuestados han expresado que el uso adecuado de los códigos tipográficos incide en la preferencia sobre un diario u otro. Por tal razón se debe escoger de manera técnica y sustentada aquellas que serán parte de la diagramación del diario y los suplementos, el periódico posee sus propios atributos que perfecciona a cada elemento que se usa en la diagramación, la importancia de la división por secciones hace que estos puedan ser independientes y permite que el elector los ubique cada tema con facilidad, evitando que se mezcle con facilidad (Guerrero 2016:16).

Figura 5. Cambios requeridos en Diario La Prensa

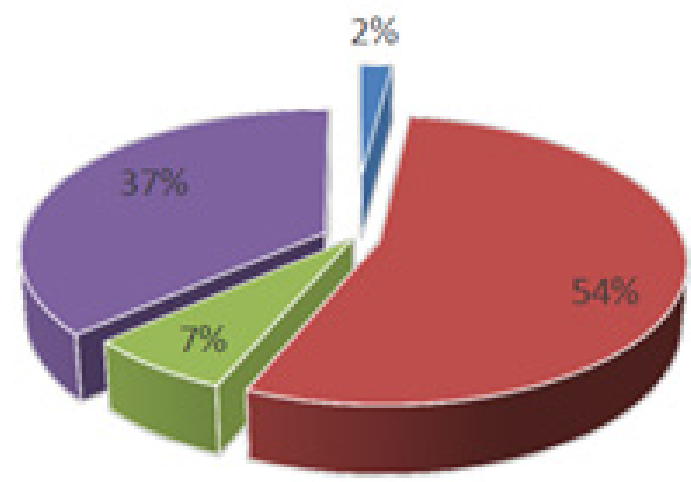

- La familias tipográficas

- L a distribución textual y fotográfica

- Los tamaños de letra

- Otros

Fuente: Elaboración propia. 


\section{Unach}

La figura 5 muestra que el 54\% de los encuestados considera que es necesario cambiar la distribución del texto e imágenes, el $2 \%$ expresa que es necesario cambiar las familias tipográficas, el $6 \%$ consideraron que es necesario cambiar los tamaños de las tipografías y el $37 \%$ consideran necesario otros aspectos.

A pesar de los comentarios positivos emitidos hacia el Diario La Prensa, los encuestados encuentran inconformidades visuales en relación a las tipografías, diseño y estructura que deberían corregirse. La belleza de una diagramación está en la comprensión del mensaje emitido y para lograr este cometido se debe aplicar herramientas como la forma, peso, contraste, proporción, simetría y armonía, que permiten construir mensajes estéticos y funcionales (Manjarrez 2003: 4)

Resultados de las encuestas para el análisis tipográfico de Diario Los Andes

Figura 6. Tipografía de la marca Diario Los Andes

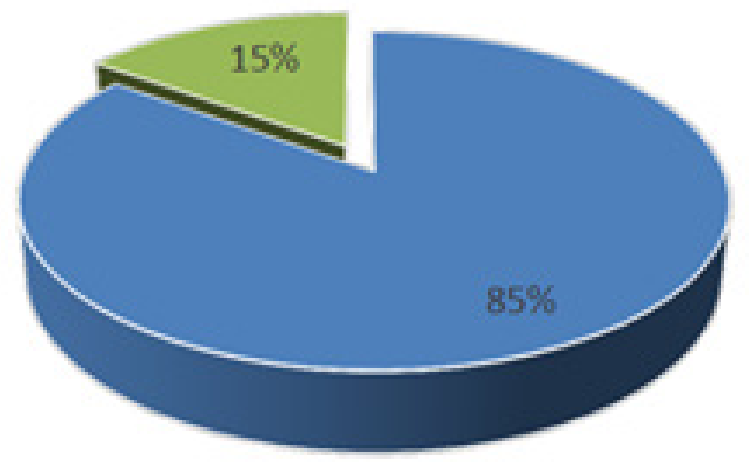

Fuente: Elaboración propia.

El 85\% de los encuestados considera que la tipografía utilizada en la marca de Diario Los Andes es apropiada. El $15 \%$ la señala que no es apropiada, según la figura 6 . Se evidencia que existen aspectos que mejorar, si bien es cierto por la trayectoria del diario las personas reconocen la marca, existen aspectos que se deben mejorar como la individualidad y personalidad. Respecto a Diario Los Andes, la simplicidad de la tipografía en su marca es beneficiosa en cuanto a su alta legibilidad, pero no le brinda individualidad a la marca. La marca es parte de la cultura de la empresa y constituye parte de todas las actividades que la empresa realiza (Klein 2002:36) 
Figura 7. Legibilidad de los cuerpos de texto Diario Los Andes

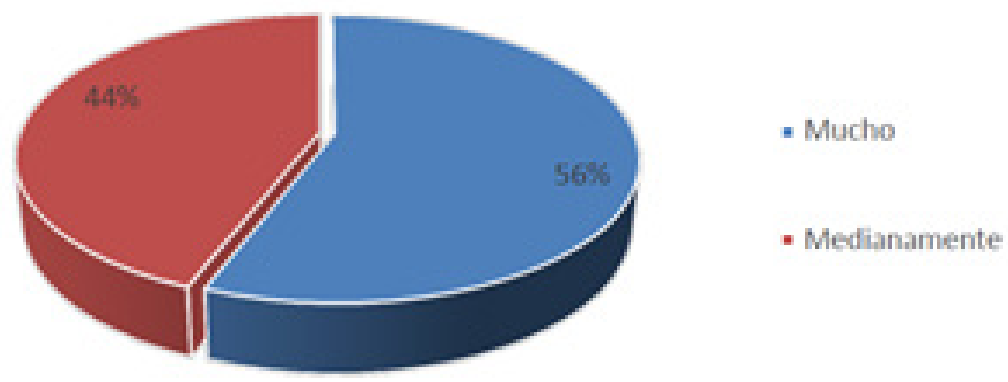

Fuente: Elaboración propia.

El 56\% de los encuestados, según la figura 7, considera que la letra utilizada en los cuerpos de texto de Diario Los Andes es óptimamente legible. Un 44\% la considera que la letra utilizada en los cuerpos de texto de Diario Los Andes es medianamente legible; se puede concluir que aún hay aspectos que mejorar.

El diseñador es solo una parte de la cadena productiva y depende de las limitaciones de otros elementos de trabajo como: papel, tintas, herramientas, maquinarias, impresión y acabados, por tanto no es libre de tomar decisiones independientes. La legibilidad abarca todos los aspectos de la diagramación, es decir, formas, familias tipográficas, ordenamiento de texto, diseño de párrafos, ilustraciones, material impreso, que se seleccionan en conjunto. (De Buen 2005:41). Diario Los Andes utiliza generalmente tipografia con serifa, la cual es muy recomendada para textos largos ya que crea una linea horizontal que no cansa la vista (Cervantes 2014:36)

Figura 8. La tipografía de Diario Los Andes invita a la lectura
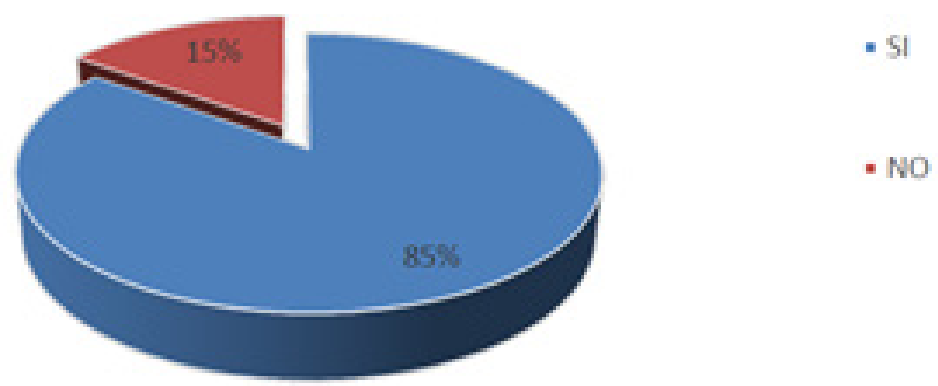

Fuente: Elaboración propia.

Como se aprecia en la figura 8 , el $85 \%$ de los encuestados considera que las tipografías utilizadas en los titulares de Diario Los Andes cumplen con la función de invitar a la lectura de las noticias, el 15\% reflexionan que no cumplen con la función de invitar a la lectura. En esta pregunta, Los Andes posee mejor percepción que Diario La Prensa, esto gracias a la regularidad en el uso de la misma familia tipográfica. La elección de una tipografía debe ser seleccionada minuciosamente porque cada una presenta proporciones particulares que la hacen única y diferente del resto (Guerrero 2016:35) 
Figura 9. Influencia de la tipografía en el interés del lector

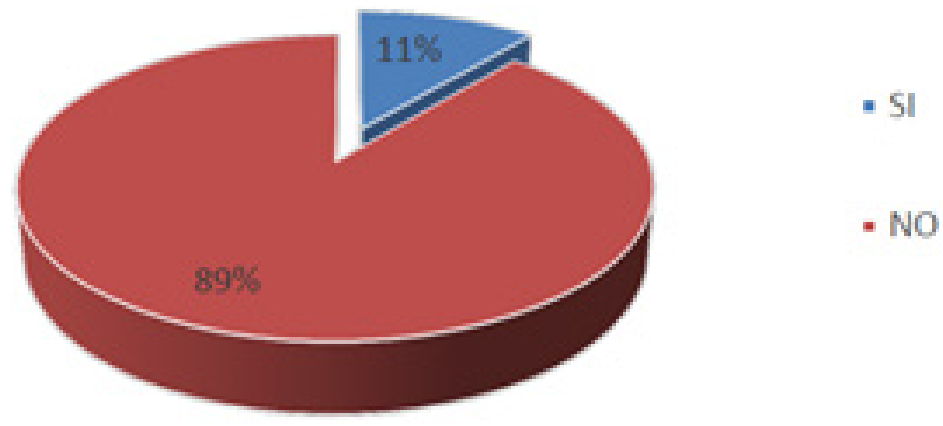

Fuente: Elaboración propia.

La figura 9 muestra que el $11 \%$ de los encuestados considera que la tipografía bien utilizada influye en el interés del lector y el $89 \%$ señala que no influye en el interés del lector, por ende, se debe cambiar a una tipografía que sea más atractiva e invite a la adquisición del ejemplar. La tipografía elegida por los diarios debe ser clara y concisa con el objetivo de comunicar con palabras que puedan ser entendidas por el usuario, sin tomar en cuenta la cantidad de información que posea el periódico (Guerrero 2016:37)

Figura 10. Cambios requeridos en Diario Los Andes

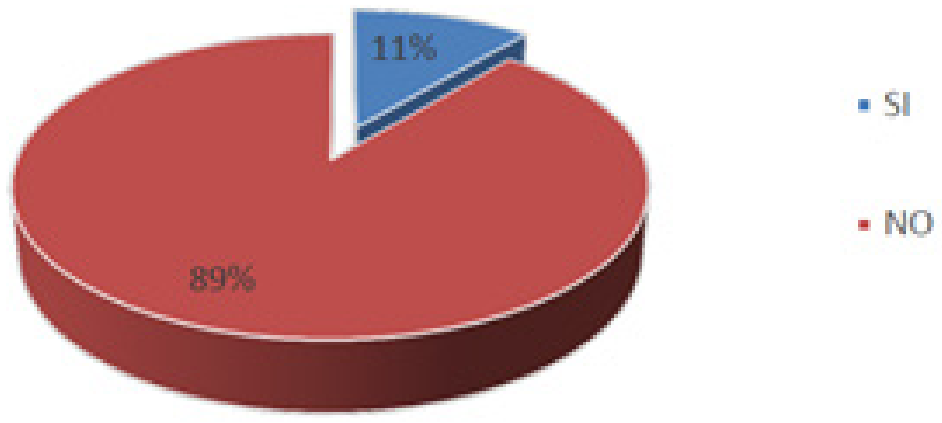

Fuente: Elaboración propia.

Según la figura 10 el 51\% de los encuestados expresó que en el periódico cambiaría las familias tipográficas, el 36\% cambiaría la distribución textual y fotográfica del periódico y el $13 \%$ los tamaños de letras. La opinión de los lectores es que el diario debe realizar cambios en las tipografías y estructura de diagramación. El receptor al comenzar la lectura, al inicio puede darse cuenta si el periódico está bien ordenado, si la tipografía es grande o pequeña, oscura o clara, bonita o fea, si todo marcha bien llegará pronto a adentrase en la lectura hasta el punto de leerla de manera consiente (De Buen 2005: 39)

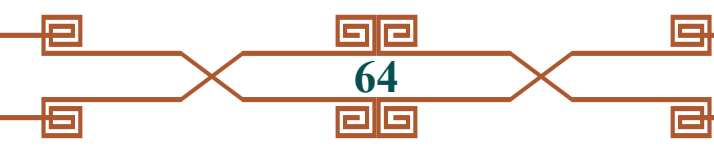




\section{CONCLUSIONES}

Una vez concluido con el análisis tipográfico de las marcas de los diarios, se concluye que:

Las dos marcas poseen alta legibilidad, sin embargo, La Prensa presenta más alta pertinencia tipológica e individualidad, gracias a que en el año 2010 el diario rediseñó su imagen. En cambio, el Diario Los Andes, posee un Isologo conformado principalmente por tipografía, que, si bien es de fácil lectura, no posee individualidad.

La Prensa posee un manual tipográfico donde se establecen los parámetros de manejo, tanto de fotografías, ilustraciones y tipografías; constan los nombres de las principales familias tipográficas utilizadas, en contraste, Diario Los Andes no posee un manual tipográfico, por tanto se evidencia desorden en su estructura, como la jerarquía tipográfica, legibilidad en el lector, lo que desencadena en el desinterés por la información publicada por el diario, influyendo en la preferencia del lector por dicho medio.

En base a los resultados de las encuestas se concluye que existen aspectos fuertes y deficiencias en los medios. En Diario La Prensa se evidencia orden en el manejo de las familias tipográficas. La marca refleja la tipografía principal y de ella se derivan las marcas para los demás productos. Se muestra una estructura formal para titulares, subtítulos, palabras claves, bloques de textos y los suplementos.

En Diario Los Andes, los lectores destacan la legibilidad de las tipografías en el diario y los suplementos, y cuestionan su diagramación ya que no existe armonía entre el texto, imagen y organización. Las páginas internas del periódico no denotan contemporaneidad y requiere actualización. El diario se percibe como un periódico antiguo o "viejo"; hecho que podría incidir en la reducción de ejemplares que salen a la venta.

El alto porcentaje de personas que afirman que la tipografía incide en el interés de los lectores, permite concluir que existe una correlación entre la jerarquía tipográfica utilizadas por los diarios y el mercado. 


\section{REFERENCIAS BIBLIOGRÁFICAS}

Castañares, W. (2007). Cultura Visual y crisis de la experiencia. Cuadernos de Información y Comunicación, $29-48$.

Cervantes, G. (2014). Manual de diseño editorial profesional. Aguascalientes: Acuario Evolución.

De Buen, J. (2005). Manual de diseño editorial (Segunda ed.). México: Santillana.

García, M. (1989). Diseño y remodelación de periódicos (Tercera ed.). La Habana: Federico Engels.

Guerrero, L. (2016). El diseño editorial. Guía para la realización de libros y revistas. Madrid: Universidad Complutense de Madrid.

Hernández, R., Fernández, C., y Baptista, P. (2010). Metodología de la Investigación (Quinta ed.). México: Mc Graw Hill.

Instituto Nacional de Estadísticas y Censos. (2014). 1,2 millones de ecuatorianos tienen un teléfono inteligente (Smartphone). Recuperado de http://www.ecuadorencifras.gob.ec/12-millones-de-ecuatorianos-tienen-un-telefono-inteligente-smartphone/

Instituto Nacional de Estadísticas y Censos. (2018). Población y Demografia. Recuperado de http://www. ecuadorencifras.gob.ec/censo-de-poblacion-y-vivienda/

Klein, N. (2002). No logo. El poder de las marcas. Toronto: Paidós.

Malhotra, N. (2008). Investigación de mercados (Quinta ed.). México: Pearson

Manjarrez, J. (2003). Diseño Editorial. Londres: Universidad de Londres.

Michel, G. (1990). Para leer a los medios, prensa, radio cine y TV. México: Trillas.

Torres, M. (2013). Evolución de la marca La Prensa y su impacto comunicacional en la ciudadanía de Riobamba. Riobamba: Unach.

Universia. (2016). Una introducción a la Teoría Lingüistica de Saussure. Recuperado de http:// noticias.universia.net. $\mathrm{mx} / \mathrm{cultura} /$ noticia/2016/09/30/1144137/introduccion-teoria-linguistica-saussure.html

Vimos, G. (2014). El código tipográfico y su importancia en el diseño de marcas de periódicos distribuidos en la ciudad de Riobamba en el periodo 2010-2012. Riobamba: Unach.
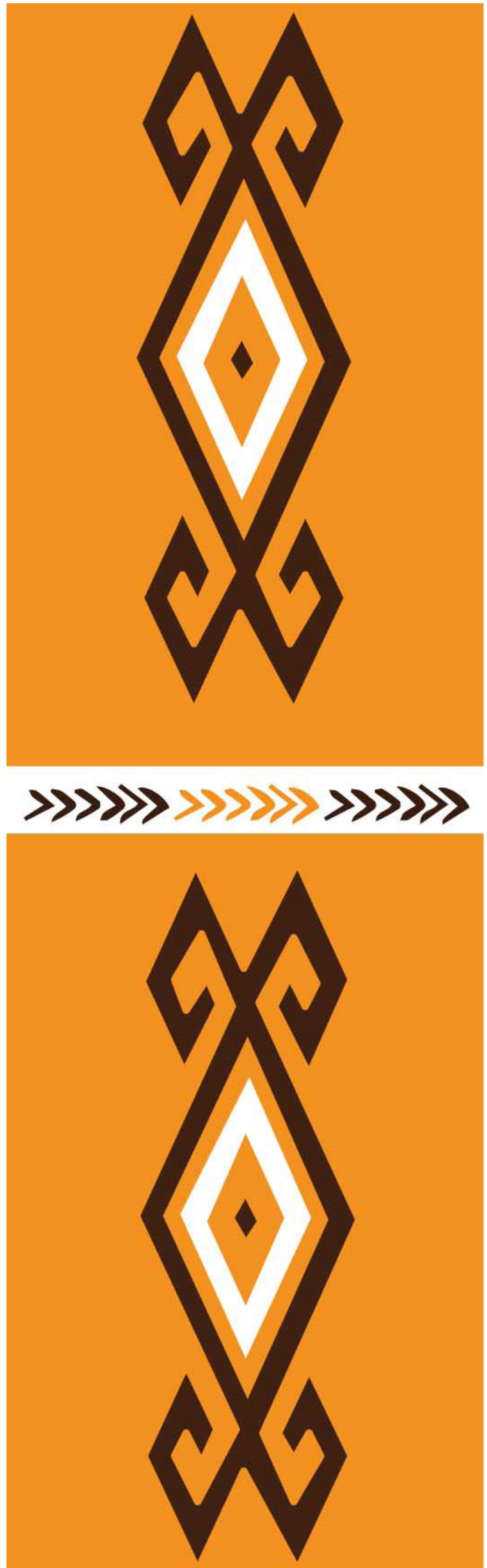